\title{
Sustainability of innovations in healthcare: A systematic review and conceptual framework for professional pharmacy services
}

\author{
Carmen Crespo-Gonzalez ${ }^{\mathrm{a}, *}$, Shalom I. Benrimoj ${ }^{\mathrm{b}}$, Moira Scerri ${ }^{\mathrm{c}}$, Victoria Garcia-Cardenas ${ }^{\mathrm{d}}$ \\ ${ }^{a}$ Graduate School of Health, University of Technology Sydney, 100 Broadway, Building 20, Lvl 10, PO Box 123 Broadway, NSW 2007, Australia \\ ${ }^{\mathrm{b}}$ Pharmaceutical Care Research Group, Faculty of Pharmacy, University of Granada, Campus Universitario Cartuja, Granada, Spain \\ ${ }^{\mathrm{c}}$ UTS Business School, University of Technology Sydney, Ultimo, NSW, Australia \\ ${ }^{\mathrm{d}}$ Graduate School of Health, University of Technology Sydney, PO Box 123 Broadway, NSW, Australia
}

\section{A R T I C L E I N F O}

\section{Keywords:}

Sustainability

Professional pharmacy service

Healthcare innovation

Framework

\begin{abstract}
A B S T R A C T
Background: Implementation science emerged to address the challenges associated with the incorporation of evidence-based innovations into practice. Once the challenge is overcome, the ultimate goal is to achieve the sustainability of innovations to promote their continuity and long-term integration. Assessment tools and measures have been designed to assess the sustainability of innovations in research and practice environments. However, the variability of assessment tools available becomes a challenge for policy makers, researchers and practitioners, particularly when deciding how to evaluate the sustainability of innovations.

Objectives: to identify conceptual approaches and assessment tools for the sustainability of healthcare innovations and to develop a specific discipline-based framework for the sustainability of professional pharmacy services.

Methods: A systematic literature review was conducted in January of 2019 using PubMed, Scopus, and Web of Science. General information regarding the conceptual approaches (based on Nilsen's classification), assessment tools and the factors affecting the sustainability of the healthcare innovations was retrieved.

Results: From 3123 articles screened, 132 articles were selected from which 106 conceptual approaches and 26 assessment tools were identified. Several key factors moderating the sustainability of the innovations in healthcare were identified (e.g. funding, adaptation). A framework for the sustainability of professional pharmacy services is proposed based on these factors. It presents three performance domains influencing the service sustainability (i.e. environment, social and economic).

Conclusions: The identified approaches in different healthcare settings have allowed the adaptation and design of a specific framework for pharmacy. The core factors included in the proposed framework are moderators of the sustainability process and should be considered in sustainability studies and evaluations. This framework will guide pharmacy practice researchers and practitioners to measure and achieve the sustainability of professional pharmacy services. Furthermore, the adaptation of this framework will allow its application to other healthcare settings. (Registration number CRD42018092160).
\end{abstract}

\section{Introduction}

Implementation science emerged to address the challenges associated with the incorporation of evidence-based innovations into practice. ${ }^{1}$ Given the complexity of implementing healthcare innovations in practice, multiple implementation models, frameworks and theories have been developed to provide guidance to funders, ${ }^{2}$ stakeholders, ${ }^{2}$ practitioners, clinicians ${ }^{3}$ and researchers. ${ }^{4-6}$ Once the challenge of translating innovations into practice is overcome, the ultimate goal is to achieve their sustainability within the practice setting, which is essential to promote their long-term integration and continuity. ${ }^{7}$

In spite of the increasing relevance of sustainability across many disciplines, the origins of the concept date back to 1960 s. $^{8}$ In 1987, the concept of sustainable development emerged as "the development that meets the needs of the present without compromising the ability of future generations to meet their needs". ${ }^{9}$ Specifically in business, sustainability has been a core goal to ensure the long-term success and viability of companies. Originally, businesses adopted a sustainability

\footnotetext{
* Corresponding author.

E-mail addresses: Carmen.crespogonzalez@student.uts.edu.au (C. Crespo-Gonzalez), shalom.benrimoj@gmail.com (S.I. Benrimoj), moira.scerri@uts.edu.au (M. Scerri), Victoria.GarciaCardenas@uts.edu.au (V. Garcia-Cardenas).
} 
bottom line approach where environmental and social aspects took second and third place to economic considerations. ${ }^{10,11}$ Since then, the notion of bottom line has been expanded to the "the triple bottom line" (TPL) concept ${ }^{11,12}$ which includes sustainability from three perspectives: people, planet, profit. The TPL is an accounting framework that measures the performance of a business not only regarding their profit and returns but also concerning its social and environmental performance. $^{13}$

However the conceptualization of sustainability within healthcare remains in debate due to the lack of consensus with terminology and the identification of factors contributing to the sustainability of innovations. ${ }^{14,15}$ Nevertheless, the various published definitions have allowed the identification of core concepts. ${ }^{15,16}$ The evolution of the literature has resulted in the development of different conceptual approaches ${ }^{14,17}$ to guide the process, determine influencing factors and to evaluate the sustainability of evidence-based innovations in healthcare. ${ }^{18}$ Assessment tools and measures have been designed to assess the sustainability of some of these innovations in both research and practice environments. ${ }^{19,20}$ However, the large range and variability of assessment tools available becomes a challenge for policy makers, researchers and practitioners, especially when deciding how to evaluate the sustainability of the innovation.

Evidence-based innovations implemented in healthcare include not only medical procedures and drug treatments, but also new health services and processes on training health care professionals, educating patients, administration, financing and service delivery models. ${ }^{21}$ There is high uncertainty associated with the incorporation of innovations in healthcare that can be related to the absence of positive outcomes to patients, the inappropriateness of the innovation in a given setting or the absence of economic rewards and incentives for the service delivered. All these factors affect directly the long-term continuity of the innovation. There is therefore, a need to identify all the factors involved in the sustainability of these innovations. ${ }^{22}$

Dispensing of medicines has traditionally been the main role and source of income in community pharmacy. The reliance on a single source of revenue may have prevented community pharmacists of maximizing their capability to provide clinical benefits to the community. Nevertheless, community pharmacists have been identifying and implementing innovations referred by the industry as professional pharmacy services, ${ }^{23}$ with their delivery being government remunerated in several countries. ${ }^{24-28}$ The importance of these professional services relies on the optimization of medication management and usage, the promotion of patient well-being and diseases prevention. The services provide improvements in clinical, economic and humanistic outcomes to patients, the population and system. ${ }^{29,30}$ Whilst the benefits have been identified, questions around the levels of adoption and implementation of such innovations remain. In addition, there is an apparent lack of evidence to guide and measure their sustained delivery.

Community pharmacy services are at a poignant phase of evolution where research on the sustainability of professional services is required.
A literature review in 2017 suggested a definition for the sustainability of pharmacy services described as, "the phase in the process of a professional pharmacy service, in which the service previously integrated into practice during the implementation phase is routinized and institutionalized over time to achieve and sustain the expected service outcomes". 7 This definition extends the traditional definition (people, planet, profit) to include service and institutional components. The service component considers the routinization of work and the institutional component considers the service value network in terms of service providers, managers, pharmacy owners, other stakeholders and the context in which the pharmacy operates. The service outcomes component of the definition includes humanistic (people), clinical (health status) and profit (economic and financial sustainability) perspectives. There is limited exploration of sustainability manly from an environmental point of view. Reduce waste generation, unnecessary packing and the importance of raising community awareness on the rationale use of medicines are some of the proposed actions to achieve an environmentally sustainable pharmacy. ${ }^{31}$ The development of a conceptual approach and assessment tools to explore and measure the sustainability of professional services in pharmacy from other perspectives are thus required. Such an approach would identify and prevent barriers to provide professional pharmacy services more competently in the long-term. Moreover, it would allow researchers and practitioners to evaluate the sustainability of these services, enable the critical monitoring, benchmarking, identification of areas of improvement and contribute to their long-term delivery of positive outcomes for the patient. If the rational use of medicines and patient's well-being are optimized, this would further deliver benefits with fewer hospitalizations and more efficient use of resources contributing to the sustainability of the healthcare system overall. ${ }^{32,33}$ The aim of this review is twofold; first to identify conceptual approaches and assessment tools in the literature related to sustainability of innovations in healthcare and secondly, to develop a conceptual framework specific to the sustainability of professional pharmacy services which can be used to guide the process of achieving long term sustainability of these services.

\section{Methods}

\section{Literature search}

A systematic literature review was undertaken following the reporting and methodological standards recommended by PRISMA. ${ }^{34}$ The literature search was conducted in January 2019 with no time restrictions in PubMed, Scopus, and Web of Science. The search strategy used (Table 1) included terms related to: sustainability (e.g. routinization, sustainability) AND healthcare (e.g. healthcare, health care sector [MeSH Terms]) AND conceptual approaches and assessment tools (e.g. model questionnaire).

Table 1

Search strategy used in each database.

\begin{tabular}{|c|c|}
\hline Database & Search criteria used \\
\hline PubMed & 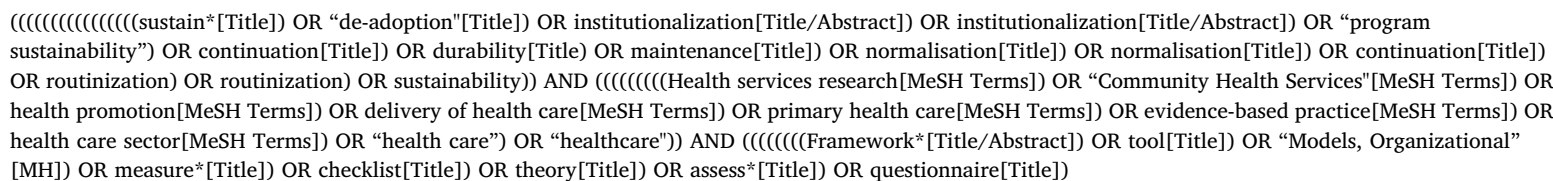 \\
\hline Scopus & $\begin{array}{l}\text { ((TITLE-ABS-KEY (sustainability OR "program sustainability") OR TITLE (maintenance OR continuation OR durability OR de adoption OR normalisation OR } \\
\text { normalisation) OR TITLE-ABS (routinization OR institutionalization))) AND(TITLE-ABS-KEY ("healthcare" OR "health care" OR "evidence-based practice" OR " } \\
\text { community health services")) AND (TITLE (framework* OR model OR questionnaire OR checklist OR tool OR theory OR measure* OR assess*)) }\end{array}$ \\
\hline Web of science & $\begin{array}{l}(\mathrm{TS}=(\text { sustainability OR "program sustainability")) AND }(\mathrm{TS}=\text { ("healthcare" OR "health care" OR "evidence-based practice")) AND }(\mathrm{TI}=(\text { framework* OR model OR } \\
\text { tool OR measure) })\end{array}$ \\
\hline
\end{tabular}


Screening

The screening, selection and review of papers included in this review was determined by a three-phase process: a review of the title and abstract of papers resulting from the search, a full text review of selected papers and then a reference review of identified papers.

The titles and abstracts of papers resulted from the search were examined, screened and irrelevant records excluded by two researchers (CCG and VGC) independently. This process was over-inclusive to ensure relevant papers were not overlooked. During the second phase, each article included was read in full text. During the third phase, reference review from the identified papers was conducted by one author (CCG) and in case of doubt was discussed with the other researchers. The following inclusion and exclusion criteria were applied in the last two phases of the process:

Papers describing a conceptual approach or assessment tool, either specifically for sustainability or as a phase in an implementation process of an innovation in healthcare were included. Papers were excluded based on the following exclusion criteria: papers describing (a) any sustainability conceptual approach or assessment tool based on innovations performed within a setting other than healthcare (e.g. school or university), (b) environmental interventions or innovations promoting physical activity or related to diet, or (c) papers not written in languages with the Latin alphabet.

The objective of this systematic review was not to evaluate randomized trials or interventions but to retrieve available sustainability conceptual approaches and assessment tools in healthcare, regardless of the outcomes achieved. Therefore, neither a qualitative assessment nor an assessment of the risk of bias of the studies was performed since the validity of the results was not considered for the outcomes of this review. This review was registered in the PROSPERO International prospective register of systematic reviews database (registration number CRD42018092160).

\section{Data extraction}

Data on conceptual approaches and assessment tools to measure sustainability was extracted from included papers. The information retrieved from the sustainability conceptual approaches was type of conceptual approach, name, aim, year, audience [see Appendix A]. Factors affecting the sustainability of health innovations in the conceptual approaches were also identified and illustrated in Table 3. The conceptual approaches identified were categorized in order to facilitate the selection of an appropriate approach, according to the taxonomy adapted from Nilsen 2015. ${ }^{35}$ A list of the terms used through the manuscript is available in Table 2.

From the articles including sustainability assessment tools the following information was retrieved: type of assessment, name, year, aim, audience, scoring scale [see Appendix A]. The sustainability factors included in these assessment tools were also retrieved (Table 4).

\section{Results}

The search identified 4189 articles, 1066 were duplicates and therefore removed. The remaining 3123 articles were screened by title and abstract. 468 full-text papers were assessed for eligibility with a total of 132 studies finally included in the qualitative analysis (Fig. 1). Only three of the included studies were pharmacy related. ${ }^{70,71,146}$ General characteristics of all the studies included are available in Appendix A.

A range of terms such as innovation, program, intervention, and project were used indistinctively in the included studies. The term innovation will be used throughout this manuscript (Table 2).

\section{Sustainability conceptual approaches}

From 132 studies, $106^{14-18,36-140}$ described a sustainability conceptual approach for innovations in healthcare. Four of these also provided an assessment tool for evaluating sustainability. ${ }^{95,105,114,141}$

\section{Conceptual approaches classification}

Based on Nilsen's classification system, 59 of the conceptual approaches included were determinant frameworks, ${ }^{14-18}, 36,40-42,46,47$, $51,57,58,60,62,65,67,69,72,73,75-80,84,85,87,89,91,95,97,99,102$, 4, 106, 109, 110, 114-121, 123, 124, 126, 128-131, 133, 136, 141-143 19 process models, ${ }^{38,39,53,56,59,61,63,70,71,81-83,88,90,96,105,111,138,143 \quad 7}$ classic theories, ${ }^{44,52,54,68,113,135,139} 9$ implementation/sustainability theories $43,45,48,55,86,98,101,103,108$ and 12 were evaluation frameworks $^{37,49,50,64,66,74,92,94,112,122,127,140 \text { [see Appendix A] }}$ (Table 3).

\section{The objectives of the conceptual approaches}


$75,77,85,87,89,97,106,118$ aimed at guiding and explaining the factors moderating the sustainability of the innovations in healthcare. In the case of process models, the majority of studies ${ }^{38,53,56,59,70,71,81,105,138}$ were orientated toward planning for sustainability through strategies and procedures necessary for achieving sustainability. The objectives of most of the classic and implementation/sustainability theories were explaining and clarifying new approaches, concepts or issues related to sustainability. ${ }^{43,45,52,86,108,139}$ The evaluation frameworks ${ }^{66,74,92,112,122}$ aimed at guiding the process for evaluating an innovation or proposing sustainability elements that could be evaluated (e.g. partnership, leadership).

\section{Audience}

The conceptual approaches were designed according to a specific objective and some also targeted a specific audience either as individuals or in groups, including researchers, ${ }^{14,87,144}$ practitioners, ${ }^{78,104,113}$ managers, ${ }^{81,100,127}$ leaders, ${ }^{56,78}$ evaluators, ${ }^{90}$ donors, governments, and non-governmental organizations. ${ }^{41,59}$

\section{Implementation and sustainability}

Some conceptual approaches considered sustainability as a concomitant phase $\mathrm{s}^{5,60,87,101,106,113,116,144}$ during the implementation of an innovation, stating both should be overall planned and measured simultaneously. However, other authors believed that sustainability starts once the innovation is integrated into a given setting and therefore, once the implementation phase is over. ${ }^{14,15,54,63,64,88,98,129,138}$ Others did not specify the relationship between these two phases. $^{36,39,56,136}$

\section{Sustainability factors identified in the conceptual approaches}

The most common factors identified as moderating the sustainability of innovations in healthcare were: financial sustainability, including funding, political environment/context, organizational capacity, leadership, partnership, staff training and evaluation, adaptability or adaptation and program evaluation. A list of all the factors identified in the conceptual approaches can be found in Table 3 .

Financial sustainability or funding was identified as a factor moderating the sustainability of innovations in healthcare in 36 of the conceptual approaches included in this review. It was defined as one of the most prominent factors contributing to sustainability, suggesting that the availability of external or internal sources of revenue is essential for the sustainability of the innovation in healthcare. ${ }^{145}$ Strategic funding was understood as having resources and plans in place for the innovation's future requirements to succeed. This was identified as critical component to ensuring continued financial support for the innovation. ${ }^{114}$

The political environment/context was determined as a factor 
Table 2

Definitions used in the manuscript.

\begin{tabular}{|c|c|}
\hline Process models ${ }^{\mathrm{a}}$ & $\begin{array}{l}\text { Those that specify the steps (stages, phases) describe and guide the process of integrating innovations into routine practice, including the } \\
\text { sustainability. An action model is a type of process model that provides practical guidance in the planning and execution of sustainability endeavors } \\
\text { and/or sustainability strategies to facilitate sustainability. }\end{array}$ \\
\hline Determinant frameworks ${ }^{\mathrm{a}}$ & $\begin{array}{l}\text { Those describing types (also known as classes or domains) of determinants and individual factors, which act as barriers and enablers (independent } \\
\text { variables) that influence sustainability outcomes (dependent variables). Some frameworks also specify relationships between some types of factors. }\end{array}$ \\
\hline Classic theories $^{\mathrm{a}}$ & Those that originate from fields external to sustainability science, which can be used to explain or understand some aspects of sustainability. \\
\hline Sustainability theories ${ }^{\mathrm{a}}$ & $\begin{array}{l}\text { Those that have been developed by sustainability or implementation researchers (from scratch or by adapting existing theories and concepts) to } \\
\text { provide understanding and explanation of aspects of sustainability. }\end{array}$ \\
\hline Evaluation frameworks ${ }^{\mathrm{a}}$ & Those that specify aspects of sustainability that could be evaluated to determine sustainability success. \\
\hline Professional pharmacy services ${ }^{\mathrm{b}}$ & $\begin{array}{l}\text { An action or set of actions undertaken in or organized by a pharmacy, delivered by a pharmacist, who applies their specialized health knowledge } \\
\text { personally or via an intermediary, with a patient, population or other health professional, to optimize the process of care, with the aim to improve } \\
\text { health outcomes and the value of healthcare. }\end{array}$ \\
\hline Individuals ${ }^{\mathrm{b}}$ & People involved in the provision of the innovation and in obtain their sustainability. \\
\hline Organization $^{\mathrm{b}}$ & The setting in which the innovation is provided. \\
\hline Local environment ${ }^{\mathrm{b}}$ & Circumstances immediately surrounding the organization(s) including the community, patients and network. \\
\hline External context ${ }^{\mathrm{b}}$ & Socioeconomic and socio-political context. \\
\hline Healthcare innovation ${ }^{\mathrm{b}}$ a c & $\begin{array}{l}\text { Healthcare innovation can be defined as the introduction of a new concept, idea, service, process, or product aimed at improving treatment, } \\
\text { diagnosis, education, outreach, prevention and research, and with the long-term goals of improving quality, safety, outcomes, efficiency and costs. }\end{array}$ \\
\hline Sustainability factors & Those elements that moderate either positively or negatively the innovation sustainability. \\
\hline Assessment tools & $\begin{array}{l}\text { We consider assessment tools as those measurement instruments such as scales, questionnaires, checklists, designed to gather and evaluate data on } \\
\text { a topic of interest from research subjects. }\end{array}$ \\
\hline Survey & $\begin{array}{l}\text { A Survey is a research method used for collecting data for statistical analysis from a pre-defined group of respondents to gain information on topics } \\
\text { of interest. For the analysis, the responses are combined to a conclusion. }\end{array}$ \\
\hline Questionnaire & $\begin{array}{l}\text { A questionnaire is a set of written questions used for retrieving information to help or benefit an individual. The questionnaire might be completed } \\
\text { by more than one individual, but the responses are not aggregated for analysis. }\end{array}$ \\
\hline Self-assessment questionnaire & A self-assessment questionnaire is a tool used to self-evaluate your state concerning a specific topic of interest. \\
\hline
\end{tabular}

a Definitions adapted from Nilsen P. Making sense of implementation theories, models and frameworks. Implement Sci. 2015 ; 10:53.

b Adapted from Moullin JC, Sabater-Hernández D, Fernandez-Llimos F, Benrimoj SI. Defining professional pharmacy services in community pharmacy. Res Social Adm Pharm. 2013; 9(6):989-995.

c Definition from Omachonu VK, Einspruch NG. Innovation in healthcare delivery systems: a conceptual framework. Innov J.2010; 15 (1):1-20.

moderating sustainability in 33 of the approaches. This factor was defined as being dynamic in nature, affecting the funding and the attention of policymakers' and the population (i.e. the changes in the political context are said to produce modifications of the innovation which may have positive or negative impact on the innovation which will influence its long-term sustainability). ${ }^{60}$ Government policies and regulations in the health system were described as affecting sustainability directly.

Twenty-one studies described organizational capacity as a range of functions that are necessary for the organization of an innovation and its ability to perform its mission. ${ }^{112}$ Organizational capacity has been stated as a vital component as it reinforces the foundations of the innovation by providing the necessary resources (i.e. time, staff, money, materials and infrastructure to ensure the innovation's long-term survival.

Twenty-nine articles introduced the concept of leadership. The presence of a leader or champion, who is responsible for managing the innovation and control of its procedures, was highlighted as crucial for the long-term survival of an innovation. A study recognized that the permanent presence of leaders facilitates sustainability because of their continued guidance, motivation and support to the innovation providers. $^{116}$

Twenty-three articles identified partnerships as a sustainability factor. Partnerships are defined as the process of cultivating connections between stakeholders for the purpose of enabling innovation. A study created a framework for the partnership process based on the individual factors (e.g. cultural perspectives, personal attributes) and identified steps in the engagement process (e.g. cultural bridging and teamwork) which have been described as an integral part of achieving sustainability. ${ }^{97}$ The importance of strong networks and relationships requiring a common vision of ideas and procedures to guarantee stakeholders commitment was highlighted as a factor which strengthens sustainability. Communication (e.g. through workshops, seminars) was defined as a strategic element which enabled the dissemination and diffusion of program activities and outcomes with stakeholders, decision-makers and the public. The necessity for clear and transparent communication was described as essential for maintaining a strong connection and relationship with other healthcare professionals. ${ }^{133,140}$

Recognition of the importance of employees to long-term sustainability was highlighted in the literature. Thus, the need for continuous staff training and evaluation of their skills are also essential to the effective implementation of sustainable innovations. Several studies also mentioned the importance of having regular meetings to provide feedback, considering staff needs and beliefs about the innovation and ensuring equitable workload. Supporting and motivating staff (e.g. with incentives) to introduce, adapt, maintain and continually improve the innovation suggests quality management principles are also crucial to achieving long-term sustainability of practices. Community and patients' inputs such as their needs and beliefs, their involvement and trust in the innovation are considered essential moderators of the sustainability of innovations.

Program adaptability/adaptation, which was defined as the degree to which an evidence-based innovation is modified to suit a particular setting or to improve fit to local conditions ${ }^{60}$ was also mentioned in thirty-one studies. One study suggested that changes happen in the innovation as a result of experience in service provision. ${ }^{89}$ Furthermore, 2 studies claimed that the adaptation of an innovation is vital for its long-term survival. ${ }^{17,89}$ Modifications of the protocol and procurement materials in concordance with the changes in the innovation have been defined as important to complete the program adaptation.

Program evaluation (monitoring) was also a factor identified in 25 studies. It was defined as assessing the progress, components, performance and outcomes of an innovation to inform, document results, provide further input in subsequent planning phases and ensure the integration of the innovation. The continual monitoring of progress throughout the implementation process including the overall evaluation of the innovation sustainability was alluded to in 2 studies. ${ }^{71,91}$ It was also suggested that program evaluation was required to justify and 


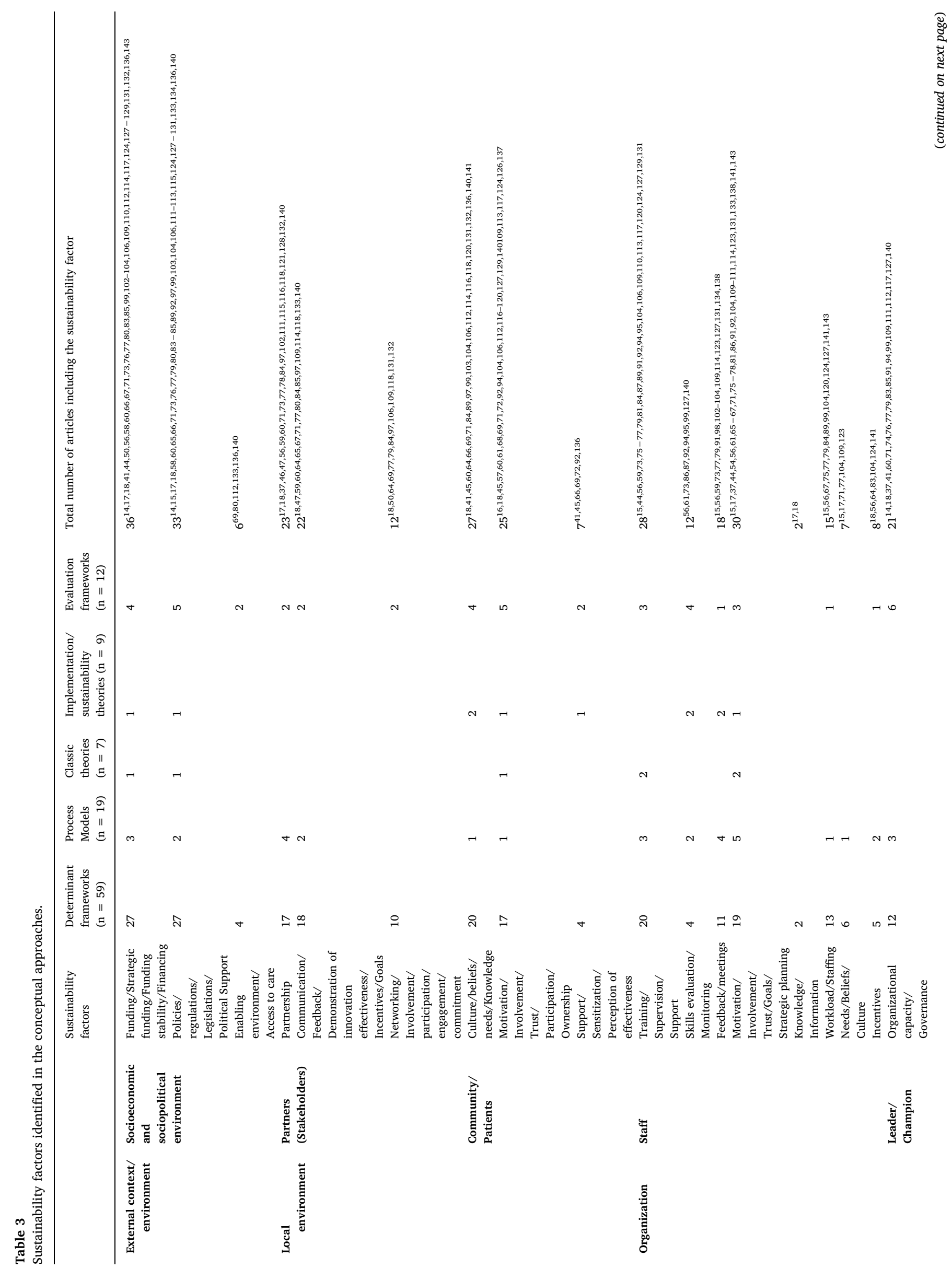




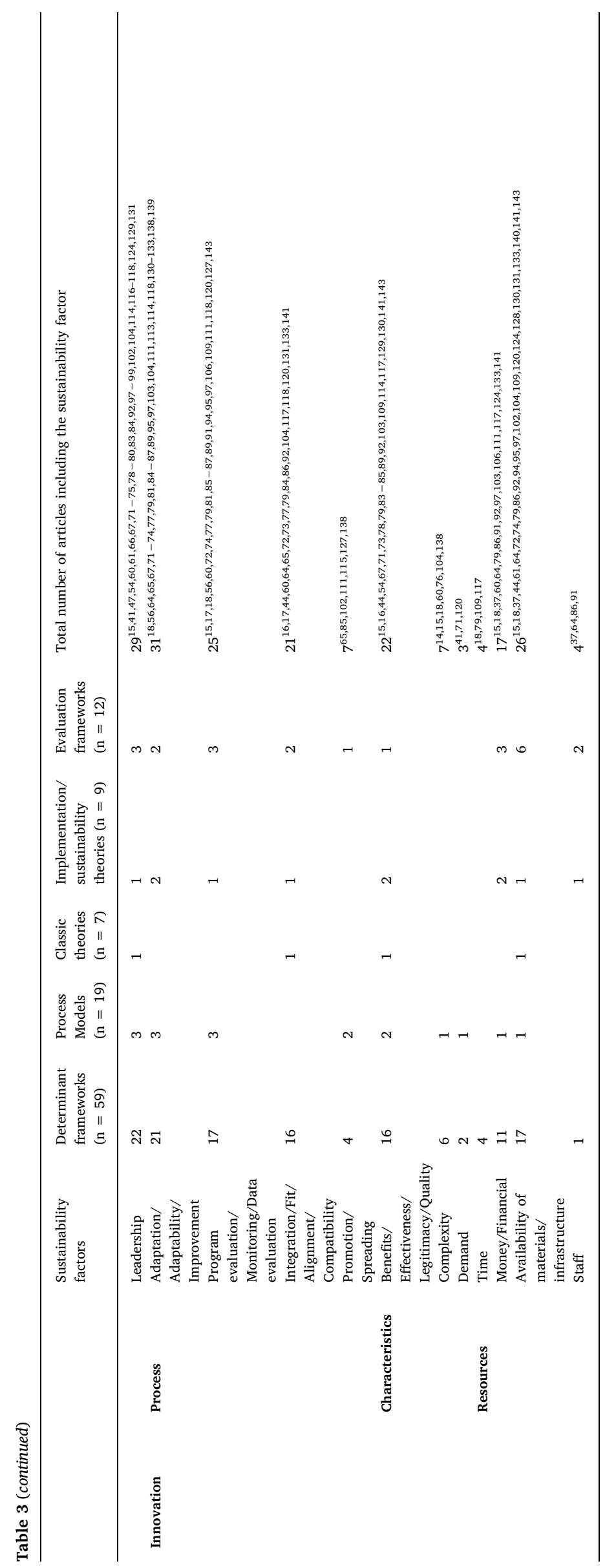




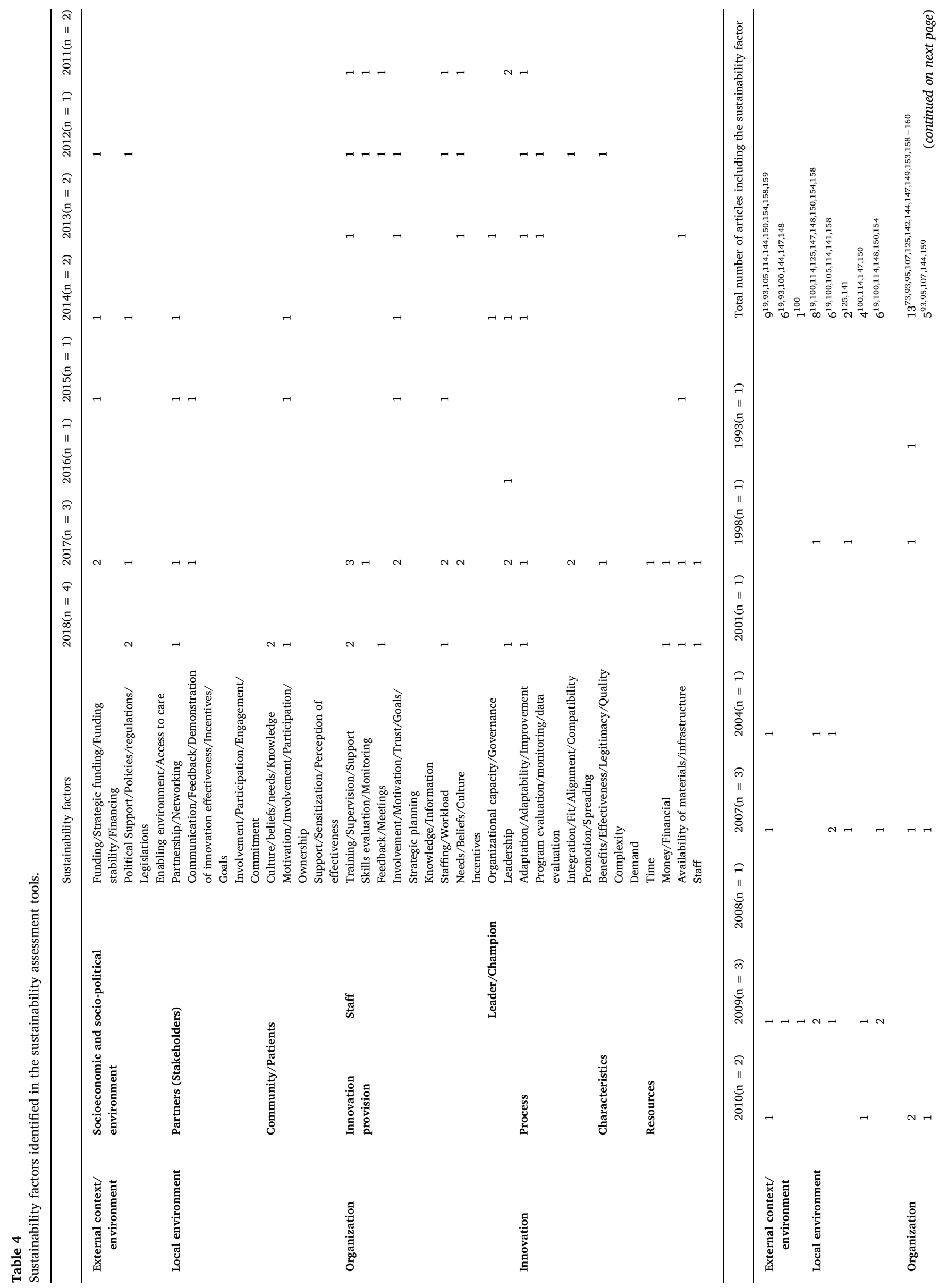






prove the innovation's effectiveness to all stakeholders (i.e. innovation partners, providers, future collaborators and the community).

\section{Sustainability assessment tools}

Assessment tools used to measure sustainability in a health setting were identified in 26 studies. $^{19,73,93,95,100,105,107,114,125,137,141-144 \text {, }}$ $146-160$

\section{Type of assessment tools}

Six of the assessment tools were questionnaires, ${ }^{142,147,148,154,157,159}$ 4 self-assessment questionnaires, ${ }^{19,95,144,153} 11$ surveys $^{73,93,105,107,114 \text {, }}$ $125,137,143,149,150,159$ and one checklist ${ }^{141}$ (Table 2).

The objective of the assessment tools

Most aimed at evaluating the performance of the innovations implemented, assessing the capacity of the innovation for sustainability ${ }^{73,95,114,125,144,149,153,158,159}$ or to evaluate the factors affecting the sustainability of the innovations. ${ }^{19,107,137,141,146}$ In addition, the design of some assessment tools was to evaluate sustainability specifically measuring the level of integration of an innovation. ${ }^{93,142,157}$

Sustainability factors in the assessment tools identified

Researchers aiming to identify sustainability factors took into account those moderating the sustainability of an innovation in the whole context of the setting in which it is implemented. ${ }^{73,95,105,114,125,144,149,153,158,159}$ Others assessed sustainability focusing on a specific sustainability factor. ${ }^{19,107,137,141,146} \mathrm{~A}$ list of all the factors identified in the assessment tools can be found in Table 4. The most common factors included in the assessment tools to evaluate the sustainability of innovations were: strategic planning, program evaluation and adaptation. Regarding the resources, the availability of practical materials was the factor most commonly included. As for the people involved in the innovation, partnership and collaboration were one of the factors most widely evaluated. Community and staff involvement were other factors most commonly assessed. Staff training and their involvement were also evaluated. Leadership and communication with stakeholders were critical factors mentioned in the assessment tools. Political support and strategic funding were the most common factors evaluated related to the external context.

\section{Assessment tools target audience}

The assessment tools were designed and administered as follows and as shown in Appendix A. Four assessment tools were created to be used by directors, managers within organizations, ${ }^{73,114,141}$ whilst others were designed for practitioners and researchers, ${ }^{93,142}$ or leaders ${ }^{149,154}$ more generally.

Theoretical based conceptual approach for the sustainability of professional pharmacy services

A theoretical framework was developed (Fig. 2). Three key principles guided the development of the framework for the sustainability of professional pharmacy services:

(1) The information retrieved from the different conceptual approaches and assessment tools identified for evaluating the sustainability of innovations in healthcare.

(2) The definition proposed for the sustainability of professional pharmacy services in a review of sustainability definitions to ensure suitability and applicability to sustainability within the pharmacy setting. ${ }^{7}$ This definition highlighted two core elements for the sustainability for professional pharmacy services, ${ }^{7}$ routinization and institutionalization:

- Routinization is the maintenance of the pharmacy's routine for the service provision through continuous improvement of the 


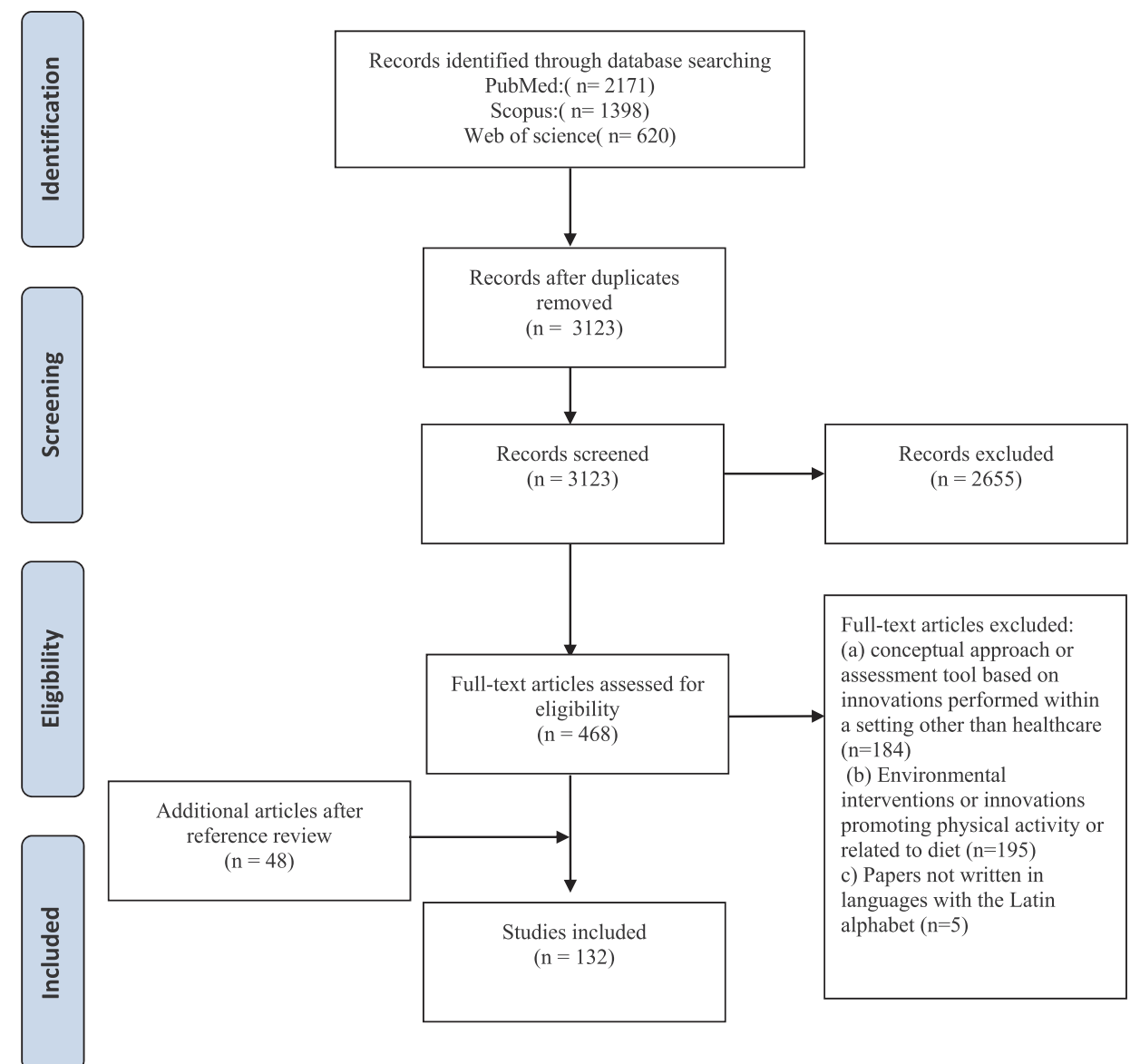

Fig. 1. Prisma flow diagram.

service's protocol and components.

- Institutionalization is the gradual adaptation of the pharmacy's context, structures, and processes, to the provision of the service.

These two core concepts are depicted in the framework proposed (Fig. 2); the routinization concept includes the professional pharmacy service (i.e. service components, the materials used during its provision and its outcomes). For institutionalization three performance domains, explained below, are involved.

(3) The three performance domains included in the TPL framework are people (social domain), planet (environment domain), profit (economic domain) ${ }^{11}$ The social performance domain refers to conducting beneficial and fair service practices for labor, human capital and the community. The environment domain involves engaging in practices that do not compromise the environmental resources for future generations. The economic domain indicates the impact of the service's practices on the economic system. ${ }^{11}$

\section{Discussion}

One hundred thirty-two studies reporting a conceptual approach or an assessment tool to understanding the sustainability of innovations in healthcare were analyzed, allowing the exploration of sustainability from different perspectives and healthcare settings. However, there was no consensus regarding the commencement of the sustainability phase; being either a stage starting after the implementation of an innovation or concomitantly occurring during implementation. A recent review ${ }^{18}$ of the literature concluded that planning for the sustainability of an innovation should be done over time and not once the implementation phase is over. This may suggest that sustainability should be considered as an ongoing process rather than as an implementation outcome.

Core factors moderating the sustainability of different innovations in healthcare have been identified in the conceptual approaches. One of the key factor seems to be the adaptability/adaptation of the service. ${ }^{18,56,64,65,67,71-74,77,79,81,84-87,89,95,97,103,104,111,113,114,118,130-133}$ 138,139 The relevance of this factor could rely on the possibility of adjusting the innovation based on different patients' needs and contexts, allowing its refinement and improving its impact and outcomes to fulfil patient's requirements. It seems reasonable that the continuous improvement of the innovation would optimize long-term maintenance of its results and benefits. Moreover, the continuous achievement of positive outcomes could improve the cost-effectiveness and cost-benefit of the innovation through higher client satisfaction and an increasing service demand. ${ }^{161}$ If an innovation is not adapted, it may not produce the expected benefits which could produce provider's loss of motivation, hindering the provision of an innovation, affecting patients and wasting resources. ${ }^{89}$

There is an intensive debate regarding the benefits of an innovation's adaptation versus its fidelity ${ }^{60,162}$ (i.e. the degree to which a service is implemented in practice as it was initially designed and intended). The relevance of fidelity has been justified by explaining its moderating effect between the innovation and its outcomes (i.e. the degree of fidelity in which an innovation is implemented is going to affect to its success). ${ }^{163}$ Some authors believe that the innovation's fidelity is essential for the internal validity to the scientific process. Therefore, the concept of adaptation at the sustainability stage, could be seen as a barrier for the maintenance of the implemented innovation and their outcomes because it could change core components of the innovation and it would produce a loss of its effectiveness. Other 


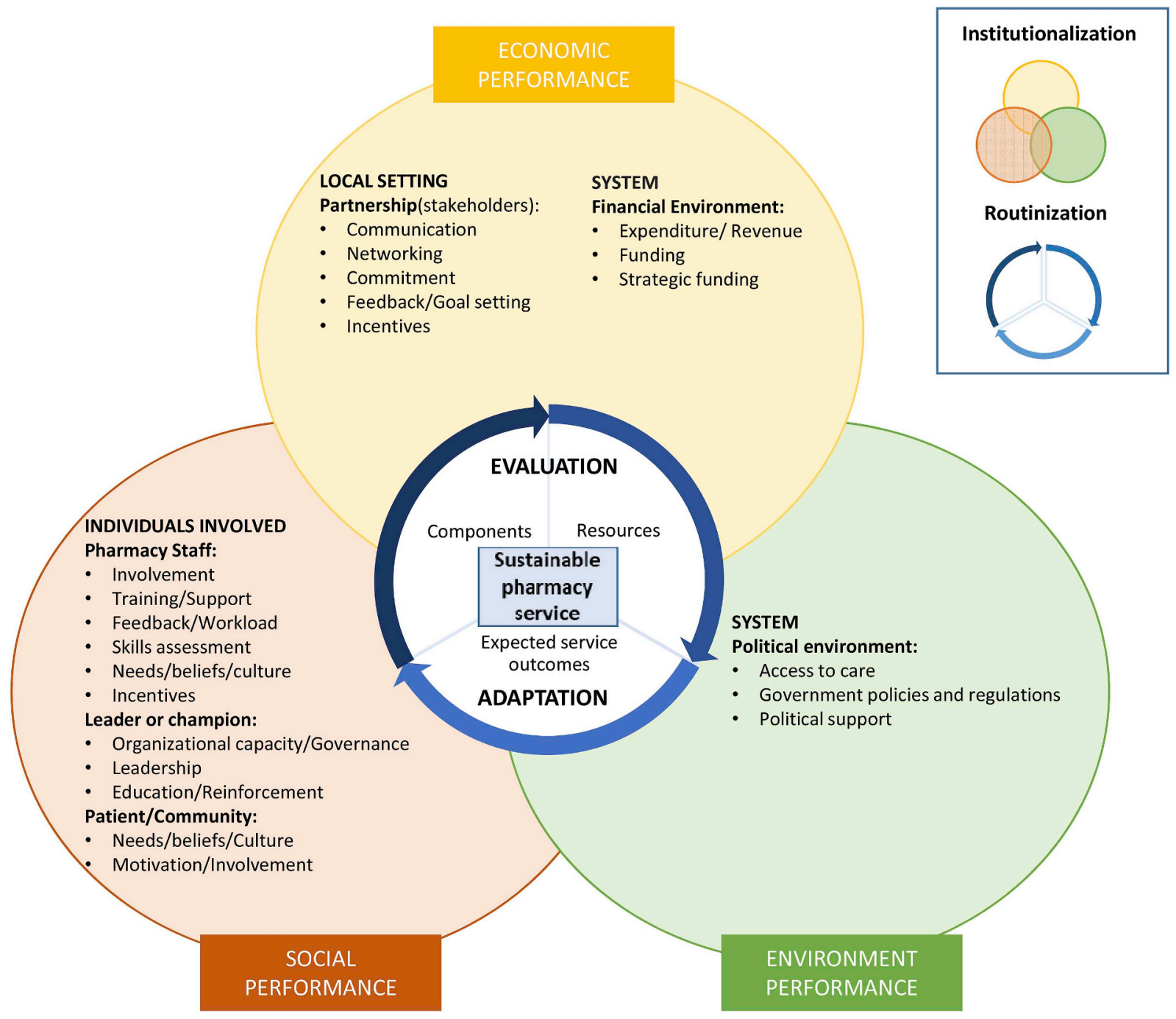

Fig. 2. Framework for the sustainability of professional services.

authors considered that both concepts are relevant and that fidelity should depend on casual mechanisms (i.e. core components of the innovation) to guarantee the innovation's effectiveness while allowing its adaptation, when necessary, to ensure sustainability. ${ }^{161,164}$

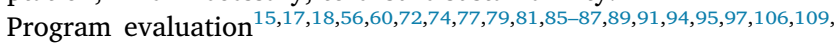
$111,118,120,127,143$ with continuous monitoring of its components and their provision is another sustainability core factor identified. The evaluation of the innovation is vital, as it is directly related to its fidelity and adaptation. The continuous monitoring of the innovation will allow the identification of the factors and components hindering its sustainability to ensure the innovation will provide benefits over time. Monitoring it seems to be the solution to identify whether an innovation is providing its expected outcomes, and if not, determining the causes.

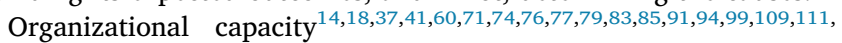
$112,117,127,140$ is essential to guarantee that the innovation has the internal support to achieve its sustainability. The importance of having resources and a strong infrastructure to ensure the optimal provision of the innovation may explain this factor relevance. Two factors, which may influence the organizational capacity, are leadership and partnership. Leadership seems to be the primary step to reach the sustainability of an innovation. The presence of a leader has been proven to facilitate and reinforce the provision of the innovation and its success. $^{165,166}$ Furthermore, partnership ${ }^{17,18,37,46,47,56,59,60,71,73,77,78,84,97 \text {, }}$ $102,111,115,116,118,121,128,132,140$ seems fundamental to achieve the innovation's long-term sustainability as it may allow collaboration with stakeholders, facilitating the interest of a broader audience. Ensuring partnership success is necessary to establish communication systems with stakeholders. Stakeholders have been reported to have a pivotal role to strengthen and provide future funding to the innovation.

Funding $14,17,18,41,44,50,56,58,60,66,67,71,73,76,77,80,83,85,99,102-104$, 106,109,110,112,114,117,124,127-129,131,132,136,143 and political environment are described as moderators of the innovation's sustainability. Many authors identified that sustainability starts when the initial funding designated for the innovation's implementation ends., ${ }^{710,131,157}$ Therefore, having a strategic plan to cover any unexpected barriers is an important consideration if sustainability is going to be achieved. Having the resources needed for an innovation should be the main priority when planning for sustainability, as the absence of funding is the main factor hindering the sustainability of innovations in healthcare settings. ${ }^{167}$ The political environment is a factor closely related to the context in which the innovation is being provided $14,15,17,18,58,60$, $65,66,71,73,76,77,79,80,83-85,89,92,97,99,103,104,106,111-113,115,124,127-131$,

133,134,136,140 The government policies and regulations will affect the setting, the characteristics of the innovation and the accessibility of the patients to the service. The changes in the political context (i.e. new government with different objectives and priorities) could affect the innovation and also produce changes in the stakeholder's interest that could even result in losing external funding for the innovation.

The availability of assessment tools to measure or evaluate the sustainability of an innovation is pivotal to identify the innovation 
barriers, assess its progress and requirements and report the innovation benefits. Some of the assessment tools retrieved provided a comprehensive guide on how to use them, their objective and also described the different items. ${ }^{17,19,95,153}$ These assessment tools included a range of factors previously identified as affecting the sustainability of innovations, with some of the factors included in most of them (e.g. staff involvement, training, strategic planning). The availability and use of practical materials (e.g. pamphlets) were one of the most common factors assessed in the assessment tools. These materials provide ongoing support for providers by presenting a more detail explanation of innovation goals and giving additional information. This additional assistance will most likely result in a more comprehensive innovation with potentially better outcomes.

\section{Framework for the sustainability of professional pharmacy services}

According to this framework, the sustainability of a professional pharmacy service is considered a dynamic process. In order to achieve a sustainable service, the three performance domains should be taken into account. These performance domains interrelate and are fundamental for successful sustainability of the service. Evaluation and continuous monitoring of the service are necessary for ensuring that all core components are working effectively. When a service is evaluated and needs to be adapted, this will affect many components. If a change of the role of the individuals involved in the service provision is necessary, the leader has to train them and further evaluate their skills to detect if they have any difficulties while providing the service. At the same time any collaborators should be informed. An agreement of the changes and the objectives of the changes may be needed to be negotiated alongside any economic implications. Implementation protocol and reports may be also modified in an effort to overcome the barriers to obtain the service's expected outcomes.

At the social performance domain there are factors depicted as moderators of sustainability. Establishing goals and providing incentives is essential to encourage and motivate the individuals involved in the provision of the professional pharmacy service (i.e. staff). As in the implementation phase, training and assessing provider's skills are two core factors directly related to the continued provision and adaptation of the service and its success. Once the implementation phase is reached, the provision of continuous training to the staff helps them to further develop and to strengthen their skills and confidence as providers promoting the ultimate goal: the sustainability of the service. Continuing training with up-to-date materials is necessary to adapt any of the service components if they are not working effectively. In this domain, the presence of a leader or champion to guide and support the service provision and its possible adaptation will facilitate that the service becomes routine practice and that it continues providing benefits once the implementation stage is completed. This champion needs to educate and reinforce the skills of the staff involved in the service provision. Furthermore, he/she needs to ensure that the service and its providers have all the resources (i.e. time, materials and money) necessaries for its provision over-time. Community and patients' needs could change from time to time and considering them will reinforce the personalized provision of the service. Cultural diversity and beliefs are other factors that need attention. Differing patient populations present different demands and fulfilling them is the key to increasing their involvement and providing an ethical and sustainable service.

In the economic performance domain, networking with stakeholders, community leaders or other healthcare professional is vital to ensure the service's maintenance and sustainability. Clear and transparent communication with goal setting will reinforce their commitment to the service. To maintain partners' interest in the service, it is necessary to provide information about service progress as well as its current and future effectiveness and benefits. The financial environment affects the service and may have implications in any adaptation. The concept of strategic funding stems from the necessity of ensuring that the pharmacy service will be supported economically and will cover future demands. Funding has highly significance for the service's sustainability and it should be considered early in service design and development.

The political environment with changes in government regulations and policies will affect the service sustainability directly (i.e. if the government changes the priorities and they cease support to some services) and is part of the environment performance domain. Furthermore, these changes can affect the service from an economic perspective because they could result in the service loss of external funding.

\section{Limitations}

Sustainability in the context of professional pharmacy services appears to be in its infancy. As a result, the literature review conducted was broad and covered different disciplines in the healthcare area. Whilst this structured literature review served the purpose and aim of this study, that is, the development of a pharmacy focused sustainability framework, taking a broader and transdisciplinary approach to the exploration of sustainability may provide further insights into the conceptual model development. Furthermore, the adaptation of this framework to different settings will provide an opportunity to be used in other disciplines in health services research.

\section{Conclusion}

This systematic literature review has revealed variations in the sustainability conceptual approaches and assessment tools identified in the healthcare area. There is still an open debate regarding the point of time at which the sustainability of an innovation is achieved. Aiming and ensuring an innovation's sustainability should be in the agenda of every healthcare professional, ensuring that an improvement and maintenance of positive outcomes in the long-term is achieved. The core factors identified as moderators of sustainability should be considered in every sustainability effort. The conceptual approaches and assessment tools available in different healthcare settings have allowed the adaptation and design of a specific conceptual approach for pharmacy. The proposed framework was created based on the factors identified as sustainability moderators in the conceptual approaches in healthcare. The framework presents different contextual domains, influencing the sustainability of professional pharmacy services. This framework will guide pharmacy practice researchers and practitioners to measure and achieve the sustainability of professional pharmacy services previously implemented.

The next phase of the research could be the validation of the framework in a qualitative study in which community pharmacists' perspectives and experiences with the provision of professional services would be explored, followed by a quantitative approach. To the best of our knowledge, a comprehensive assessment tool for evaluating the sustainability of professional pharmacy services is yet to be developed, representing another area for future research.

\section{Funding}

This research did not receive any specific grant from funding agencies in the public, commercial, or not-for-profit sectors.

\section{CRediT authorship contribution statement}

Carmen Crespo-Gonzalez: Conceptualization, Methodology, Formal analysis, Investigation, Writing - original draft, Writing - review \& editing. Shalom I. Benrimoj: Conceptualization, Methodology, Writing - review \& editing, Supervision. Moira Scerri: Writing - review \& editing, Supervision. Victoria Garcia-Cardenas: Conceptualization, Methodology, Investigation, Writing - review \& editing, Supervision. 


\section{Declaration of competing interest}

None.

\section{Appendix A. Supplementary data}

Supplementary data related to this article can be found at https:// doi.org/10.1016/j.sapharm.2020.01.015.

\section{References}

1. Eccles MP, Mittman BS. Welcome to implementation science. Implement Sci. 2006;1(1):1

2. Wandersman A, Duffy J, Flaspohler P, et al. Bridging the gap between prevention research and practice: the interactive systems framework for dissemination and implementation. Am J Community Psychol. 2008;41(3-4):171-181.

3. Rycroft-Malone J, Seers K, Chandler J, et al. The role of evidence, context, and facilitation in an implementation trial: implications for the development of the PARIHS framework. Implement Sci. 2013;8:28.

4. Greenhalgh T, Robert G, McFarlane F, Bate P, Kyriakidou O. Diffusion of innovations in service organisations: systematic review and recommendations. Milbank $Q$ 2004;82.

5. Simpson DD, Flynn PM. Moving innovations into treatment: a stage-based approach to program change. J Subst Abuse Treat. 2007;33(2):111-120.

6. Moullin JC, Sabater-Hernández D, Fernandez-Llimos F, Benrimoj SI. A systematic review of implementation frameworks of innovations in healthcare and resulting generic implementation framework. Health Res Pol Syst. 2015;13(1):16.

7. Crespo-Gonzalez C, Garcia-Cardenas V, Benrimoj SI. The next phase in professional services research: from implementation to sustainability. Res Soc Adm Pharm 2017;13(5):896-901.

8. Du Pisani JA. Sustainable development-historical roots of the concept. Environ Sci. 2006;3(2):83-96.

9. Brundtland GH. World commission on environment and development. Environ Pol Law. 1985;14(1):26-30.

10. Carter CR, Rogers DS. A framework of sustainable supply chain management: moving toward new theory. Int J Phys Distrib Logist Manag. 2008;38(5):360-387.

11. Elkington J. Partnerships from cannibals with forks: the triple bottom line of 21st-century business. Environ Qual Manag. 1998;8(1):37-51.

12. Henriques A, Richardson J. The Triple Bottom Line: Does it All Add up. Routledge; 2013.

13. Slaper TF, Hall TJ. The triple bottom line: what is it and how does it work. Indiana Bus Rev. 2011;86(1):4-8.

14. Scheirer MA, Dearing JW. An agenda for research on the sustainability of public health programs. Am J Publ Health. 2011;101(11):2059-2067.

15. Johnson K, Hays C, Center H, Daley C. Building capacity and sustainable prevention innovations: a sustainability planning model. Eval Progr Plann. 2004;27(2):135-149.

16. Shediac-Rizkallah MC, Bone LR. Planning for the sustainability of community-based health programs: conceptual frameworks and future directions for research, practice and policy. Health Educ Res. 1998;13(1):87-108.

17. Racine DP. Reliable effectiveness: a theory on sustaining and replicating worthwhile innovations. Adm Policy Ment Health. 2006;33(3):356-387.

18. Lennox L, Maher L, Reed J. Navigating the sustainability landscape: a systematic review of sustainability approaches in healthcare. Implement Sci. 2018:13(1):27.

19. Luke DA, Calhoun A, Robichaux CB, Moreland-Russell S, Elliott MB. The program sustainability assessment tool: a new instrument for public health programs. Prev Chronic Dis. 2014;11 2014

20. Sarriot EG, Winch PJ, Ryan LJ, et al. A methodological approach and framework for sustainability assessment in NGO- implemented primary health care programs. Int $J$ Health Plann Manag. 2004;19(1):23-41.

21. Dixon-Woods M, Amalberti R, Goodman S, Bergman B, Glasziou P. Problems and promises of innovation: why healthcare needs to rethink its love/hate relationship with the new. BMJ Qual Saf. 2011;20(Suppl 1):i47-51.

22. Goh CY, Marimuthu MJP-S, Sciences B. The Path towards Healthcare Sustainability: The Role of Organisational Commitment. 2016; 2016:587-592.

23. Moullin JC, Sabater-Hernández D, Fernandez-Llimos F, Benrimoj SI. Defining professional pharmacy services in community pharmacy. Res Soc Adm Pharm. 2013;9(6):989-995.

24. Houle SK, Grindrod KA, Chatterley T, Tsuyuki RT. Paying pharmacists for patient care: a systematic review of remunerated pharmacy clinical care services. Can Pharm J. 2014;147(4):209-232.

25. Richardson E, Pollock AM. Community pharmacy: moving from dispensing to diagnosis and treatment. Br Med J. 2010;340:c2298.

26. Scott DM. United States health care system: a pharmacy perspective. Can J Hosp Pharm. 2016;69(4):306-315.

27. Canada CPA. A review of pharmacy services in Canada and the health and economic evidence. . Available from: https://www.pharmacists.ca/cpha-ca/assets/File/cphaon-the-issues/Pharmacy\%20Services\%20Report\%201.pdf; 2016.

28. Moles RJ, Stehlik P. Pharmacy practice in Australia. Can J Hosp Pharm. 2015;68(5):418-426.

29. Pande S, Hiller JE, Nkansah N, Bero L. The effect of pharmacist-provided non-dispensing services on patient outcomes, health service utilisation and costs in lowand middle-income countries. Cochrane Database Syst Rev. 2013(2).
30. Yuan C, Ding Y, Zhou K, Huang Y, Xi X. Clinical outcomes of community pharmacy services. Syst. Rev. Meta-Anal. 2019;27(5):e567-e587.

31. Lau L. Filling a greener prescription: a movement towards environmentally sustainable pharmacy practice. Can Pharm $J$ : CPJ = Revue des pharmaciens du Canada: RPC. 2016;149(4):202-203.

32. Malet-Larrea A, Goyenechea E, García-Cárdenas V, et al. The impact of a medication review with follow-up service on hospital admissions in aged polypharmacy patients. Br J Clin Pharmacol. 2016;82(3):831-838.

33. Dalton K, Byrne S. Role of the pharmacist in reducing healthcare costs: current insights. Integrated Pharm Res Pract. 2017;6:37-46.

34. Moher D, Liberati A, Tetzlaff J, Altman DG. Preferred reporting items for systematic reviews and meta-analyses: the PRISMA statement. PLoS Med. 2009;6:e1000097.

35. Nilsen P. Making sense of implementation theories, models and frameworks. Implement Sci. 2015;10:53

36. Lo Presti L, Testa M, Marino V, Singer P. Engagement in healthcare systems: adopting digital tools for a sustainable approach. Sustainability. 2019;11(1).

37. Hamzeh J, Pluye P, Bush PL, Ruchon C, Vedel I, Hudon C. Towards an assessment for organizational participatory research health partnerships: a systematic mixed studies review with framework synthesis. Eval Progr Plann. 2019;73:116-128.

38. Yu CH, Gall Casey C, Ke C, Lebovic G, Straus SE. Process evaluation of the diabetes Canada guidelines dissemination strategy using the reach effectiveness adoption implementation maintenance (RE-AIM) framework. Can $J$ Diabetes. 2019;43(4):263-270. https://doi.org/10.1016/j.jcjd.2018.08.189.

39. Whitehead J, Pearson AL, Lawrenson R, Atatoa-Carr P. Framework for examining the spatial equity and sustainability of general practitioner services. Aust $J$ Rural Health. 2018;26(5):336-341.

40. Trautner BW, Prasad P, Grigoryan L, et al. Protocol to disseminate a hospital-site controlled intervention using audit and feedback to implement guidelines concerning inappropriate treatment of asymptomatic bacteriuria. Implement Sci. 2018;13(1):16

41. Scott R, Jindal-Snape D, Manwaring G. Exploring the relationship between volunteering and hospice sustainability in the UK: a theoretical model. Int J Palliat Nurs;24(5):212-219.

42. Scott NA, Vian T, Kaiser JL, et al. Listening to the community: using formative research to strengthen maternity waiting homes in Zambia. PloS One. 2018;13(3):e0194535

43. Rapport F, Clay-Williams R, Churruca K, Shih P, Hogden A, Braithwaite J. The struggle of translating science into action: foundational concepts of Implement. Sci J Eval Clin Pract. 2018;24(1):117-126.

44. Perez-Escamilla R, Cavallera V, Tomlinson M, Dua T. Scaling up integrated early childhood development programs: lessons from four countries. Child Care Health Dev. 2018;44(1):50-61.

45. Nyholm L, Salmela S, Nyström L, Koskinen C. Sustainability in care through an ethical practice model. Nurs Ethics. 2018;25(2):264-272.

46. Mormina M, Pinder S. A conceptual framework for training of trainers (ToT) interventions in global health. Glob Health. 2018;14(1).

47. Klinga C, Hasson H, Andreen Sachs M, Hansson J. Understanding the dynamics of sustainable change: a 20-year case study of integrated health and social care. BMC Health Serv Res. 2018;18(1):400.

48. Johansen F, Loorbach D, Stoopendaal A. Exploring a transition in Dutch healthcare $J$ Health Organisat Manag. 2018;32(7):875-890.

49. Iandolo F, Vito P, Fulco I, Loia F. From health technology assessment to health technology sustainability. Sustainability. 2018;10(12)

50. Harding P, Burge A, Walter K, et al. Advanced musculoskeletal physiotherapists in post arthroplasty review clinics: a state wide implementation program evaluation. Physiotherapy. 2018;104(1):98-106

51. Greenhalgh T, Wherton J, Papoutsi C, et al. Analysing the role of complexity in explaining the fortunes of technology programmes: empirical application of the NASSS framework. BMC Med. 2018;16(1).

52. Gilissen J, Pivodic L, Gastmans C, et al. How to achieve the desired outcomes of advance care planning in nursing homes: a theory of change. BMC Geriatr. 2018;18(1)

53. García-Goñi M, Fouda A, Calder RV, Paolucci F. A new funding model for a chroniccare focused healthcare system in Australia. Health Policy Technol. 2018;7(3):293-301.

54. Flynn R, Newton AS, Rotter T, et al. The sustainability of Lean in pediatric healthcare: a realist review. Syst Rev. 2018;7(1):137

55. deRiel E, Puttkammer N, Hyppolite N, et al. Success factors for implementing and sustaining a mature electronic medical record in a low-resource setting: a case study of iSante in Haiti. Health Pol Plann. 2018;33(2):237-246.

56. Chu KWK, Cheung LLW. Incorporating sustainability in small health-care facilities: an integrated model. Leader Health Serv. 2018;31(4):441-451.

57. Campbell F, Lawton J, Rankin D, et al. Follow-Up Support for Effective type 1 Diabetes self-management (The FUSED Model): a systematic review and meta-eth nography of the barriers, facilitators and recommendations for sustaining selfmanagement skills after attending a structured education programme. BMC Health Serv Res. 2018;18(1):898.

58. Basaza R, Kinegyere A, Mutatina B, Sewankambo N. National framework for the sustainability OF health knowledge translation initiatives IN Uganda. Int J Technol Assess Health Care. 2018:34(1):120-128.

59. Story WT, LeBan K, Altobelli LC, et al. Institutionalizing community-focused maternal, newborn, and child health strategies to strengthen health systems: a new framework for the Sustainable Development Goal era. Glob Health. 2017;13(1).

60. Shelton RC, Cooper BR, Stirman SW. The sustainability of evidence-based interventions and practices in public health and health care. Annu Rev Publ Health. 2018;39:55-76. 
61. Harris C, Allen K, Waller C, et al. Sustainability in Health care by Allocating Resources Effectively (SHARE) 5: developing a model for evidence-driven resource allocation in a local healthcare setting. BMC Health Serv Res. 2017;17(1).

62. Greenhalgh T, Wherton J, Papoutsi C, et al. Beyond adoption: a new framework for theorizing and evaluating nonadoption, abandonment, and challenges to the scaleup, spread, and sustainability of health and care technologies. JMIR. 2017;19(11).

63. Brown CH, Curran G, Palinkas LA, et al. An overview of research and evaluation designs for dissemination and implementation. Annu Rev Publ Health. 2017;38:1-22.

64. Azeredo TB, Oliveira MA, Santos-Pinto CDB, Miranda ES, Osorio-de-Castro CGS. Sustainability of ARV provision in developing countries: challenging a framework based on program history. Ciência Saúde Coletiva. 2017;22(8):2581-2594.

65. Ament SMC, Gillissen F, Moser A, et al. Factors associated with sustainability of 2 quality improvement programs after achieving early implementation success. A qualitative case study. J Eval Clin Pract. 2017;23(6):1135-1143.

66. Song B, Sun Q, Li Y, Que CJS. Evaluating the sustainability of community-based long-term care programmes: a hybrid multi-criteria decision making approach. Sustainability. 2016;8(7):657.

67. Schalock RL, Verdugo M, Lee TJE, Planning P. A systematic approach to an organization's sustainability. Eval Progr Plann. 2016;56:56-63.

68. Roy M, Czaicki N, Holmes C, et al. Understanding sustained retention in HIV/AIDS care and treatment: a synthetic review. Curr HIV AIDS Rep. 2016;13(3):177-185.

69. Radhakrishnan K, Xie B, Berkley A, Kim MJHsr. Barriers and facilitators for sustainability of tele-homecare programs: a systematic review. Health Serv Res. 2016;51(1):48-75.

70. Moullin JC, Sabater-Hernandez D, Benrimoj SI. Model for the evaluation of implementation programs and professional pharmacy services. Res Soc Adm Pharm. 2016;12(3):515-522.

71. Moullin JC, Sabater-Hernandez D, Benrimoj SI. Qualitative study on the implementation of professional pharmacy services in Australian community pharmacies using framework analysis. BMC Health Serv Res. 2016;16.

72. Iwelunmor J, Blackstone S, Veira D, et al. Toward the sustainability of health interventions implemented in sub-Saharan Africa: a systematic review and conceptual framework. Implement Sci. 2016;11:43

73. Hodge LM, Turner KMT. Sustained implementation of evidence-based programs in disadvantaged communities: a conceptual framework of supporting factors. Am J Community Psychol. 2016:192-210.

74. Shigayeva A, Coker RJ. Communicable disease control programmes and health systems: an analytical approach to sustainability. Health Pol Plann. 2015;30(3):368-385.

75. Lean M, Leavey G, Killaspy H, et al. Barriers to the sustainability of an intervention designed to improve patient engagement within NHS mental health rehabilitation units: a qualitative study nested within a randomised controlled trial. BMC Psychiatr. 2015;15(1):209.

76. Hunter SB, Han B, Slaughter ME, Godley SH, Garner BR. Associations between implementation characteristics and evidence-based practice sustainment: a study of the Adolescent Community Reinforcement Approach. Implement Sci. 2015;10:173.

77. Fox A, Gardner G, Osborne S. A theoretical framework to support research of health service innovation. Aust Health Rev. 2015;39(1):70-75.

78. Fleiszer AR, Semenic SE, Ritchie JA, Richer MC, Denis JL. The sustainability of healthcare innovations: a concept analysis. J Adv Nurs. 2015;71(7):1484-1498.

79. Fleiszer AR, Semenic SE, Ritchie JA, Richer MC, Denis JL. An organizational perspective on the long-term sustainability of a nursing best practice guidelines program: a case study. BMC Health Serv Res. 2015;15:535.

80. Birch S, Murphy GT, MacKenzie A, Cumming J. In place of fear: aligning health care planning with system objectives to achieve financial sustainability. $J$ Health Serv Res Pol. 2015;20(2):109-114

81. Persaud DD. Enhancing learning, innovation, adaptation, and sustainability in health care organizations: the ELIAS performance management framework. Health Care Manag. 2014;33(3):183-204.

82. Nyström ME, Strehlenert H, Hansson J, HJBhsr Hasson. Strategies to facilitate implementation and sustainability of large system transformations: a case study of a national program for improving quality of care for elderly people. BMC Health Serv Res. 2014;14(1):401

83. Amaya AB, Caceres CF, Spicer N, Balabanova D. After the Global Fund: who can sustain the HIV/AIDS response in Peru and how? Global Publ Health. 2014;9(12):176-197.

84. Stirman SW, Miller CJ, Toder K, Calloway A. Development of a framework and coding system for modifications and adaptations of evidence-based interventions. Implement Sci. 2013;8(1).

85. Schell SF, Luke DA, Schooley MW, et al. Public health program capacity for sustainability: a new framework. Implement Sci. 2013;8(1).

86. Johnson K, Collins D, AJJoCP Wandersman. Sustaining innovations in communit prevention systems: a data-informed sustainability strategy. $J$ Community Psychol. 2013;41(3):322-340

87. Isabalija SR, Mbarika V, GMJIjot Kituyi. A framework for sustainable implementation of e-medicine in transitioning countries. Int. J. Telemed. App. 2013;2013:8.

88. Chaudoir SR, Dugan AG, Barr CHJIS. Measuring factors affecting implementation of health innovations: a systematic review of structural, organizational, provider, patient, and innovation level measures. Implement Sci. 2013;8(1):22.

89. Chambers DA, Glasgow RE, Stange KC. The dynamic sustainability framework: addressing the paradox of sustainment amid ongoing change. Implement Sci. 2013;8(1)

90. Blanchet K, Girois S. Selection of sustainability indicators for health services in challenging environments: balancing scientific approach with political engagement. Eval Progr Plann. 2013;38:28-32.
91. Parand A, Benn J, Burnett S, Pinto A, Vincent C. Strategies for sustaining a quality improvement collaborative and its patient safety gains. Int J Qual Health Care. 2012;24(4):380-390.

92. Okeibunor J, Bump J, Zouré HG, Sékétéli A, Godin C, Amazigo UV. A model for evaluating the sustainability of community-directed treatment with ivermectin in the African Program for Onchocerciasis Control. Int J Health Plann Manag. 2012;27(3):257-271.

93. Finch TL, Mair FS, O'Donnell C, Murray E, May CR. From theory to 'measurement' in complex interventions: methodological lessons from the development of an e-health normalisation instrument. BMC Med Res Methodol. 2012;12:69.

94. Blackford J, Street A. Tracking the route to sustainability: a service evaluation too for an advance care planning model developed for community palliative care services. J Clin Nurs. 2012;21(15-16):2136-2148.

95. Slaghuis SS, Strating MM, Bal RA, Nieboer AP. A framework and a measurement instrument for sustainability of work practices in long-term care. BMC Health Serv Res. 2011;11

96. Melnyk BM, Fineout-Overholt E, Gallagher-Ford L, Stillwell SB. Evidence-based practice, step by step: sustaining evidence-based practice through organizational policies and an innovative model. Am J Nurs. 2011;111(9):57-60.

97. Leffers J, Mitchell E. Conceptual model for partnership and sustainability in global health. Publ Health Nurs. 2011;28(1):91-102.

98. Campbell S, Pieters K, Mullen K-A, Reece R, Reid R. Examining sustainability in a hospital setting: case of smoking cessation. Implement Sci. 2011;6(1):108.

99. Aarons GA, Hurlburt M, Horwitz SM. Advancing a conceptual model of evidencebased practice implementation in public service sectors. Adm Policy Ment Health. 2011;38(1):4-23

100. Sarriot E, Ricca J, Ryan L, Basnet J, Arscott-Mills S. Measuring sustainability as a programming tool for health sector investments: report from a pilot sustainability assessment in five Nepalese health districts. Int $J$ Health Plann Manag. 2009;24(4):326-350.

101. May CR, Mair F, Finch T, et al. Development of a theory of implementation and integration: normalization process theory. Implement Sci. 2009;4(1)

102. Bray P, Cummings DM, Wolf M, Massing MW, Reaves J. After the collaborative is over: what sustains quality improvement initiatives in primary care practices? Joint Comm J Qual Patient Saf. 2009;35(10):502-AP503.

103. Gruen RL, Elliott JH, Nolan ML, et al. Sustainability science: an integrated approach for health-programme planning. Lancet. 2008;372(9649):1579-1589.

104. Feldstein AC, Glasgow RE. A practical, robust implementation and sustainability model (PRISM) for integrating research findings into practice. Joint Comm J Qual Patient Saf. 2008;34(4):228-243.

105. Sridharan S, Go S, Zinzow H, Gray A, Gutierrez Barrett M. Analysis of strategic plan to assess planning for sustainability of comprehensive community initiatives. Eval Progr Plann. 2007;30(1):105-113.

106. Nelson DE, Reynolds JH, Luke DA, et al. Successfully maintaining program funding during trying times: lessons from tobacco control programs in five states. $J$ Publ Health Manag Pract. 2007;13(6):612-620.

107. Amazigo U, Okeibunor J, Matovu V, Zoure H, Bump J, Seketeli A. Performance of predictors: evaluating sustainability in community-directed treatment projects of the African programme for onchocerciasis control. Soc Sci Med. 2007;64(10):2070-2082

108. May C. A rational model for assessing and evaluating complex interventions in health care. BMC Health Serv Res. 2006;6(1):86

109. Israr SM, Islam A. Good governance and sustainability: a case study from Pakistan. Int $J$ Health Plann Manag. 2006;21(4):313-325.

110. Blasinsky M, Goldman HH, Unutzer J. Project IMPACT: a report on barriers and facilitators to sustainability. Adm Policy Ment Health. 2006;33(6):718-729.

111. Nilsen P, Timpka T, Nordenfelt L, Lindqvist K. Towards improved understanding of injury prevention program sustainability. Saf Sci. 2005;43(10):815-833.

112. Sarriot EG, Winch PJ, Ryan LJ, et al. Qualitative research to make practical sense of sustainability in primary health care projects implemented by non-governmental organizations. Int J Health Plann Manag. 2004;19(1):3-22.

113. Pluye P, Potvin L, Denis J. Making public health programs last: conceptualizing sustainability. Eval Progr Plann. 2004;27(2):121-133.

114. Mancini JA, Marek L. Sustaining community-based programs for families: con ceptualization and measurement. Fam Relat. 2004;53(4):339-347.

115. Jana S, Basu I, Rotheram-Borus MJ, Newman P. The Sonagachi Project: a sustainable community intervention program. AIDS Educ Prev. 2004;16(5):405-414

116. Sivaram S, Celentano D. Training outreach workers for AIDS prevention in rural India: is it sustainable? Health Pol Plann. 2003;18(4):411-420.

117. Evashwick C. Organizational characteristics of successful innovative health care programs sustained over time. Fam Community Health. 2003;26(3):177-193.

118. Alexander JA, Weiner BJ, Metzger ME, et al. Sustainability of collaborative capacity in community health partnerships. Med Care Res Rev. 2003;60(4 Suppl):130s-160s.

119. Wong L-C, Amega B, Barker R, et al. Factors supporting sustainability of a community-based scabies control program. Aust J Dermatol. 2002;43(4):274-277.

120. Gruen RL, Weeramanthri TS, Bailie RS. Outreach and improved access to specialist services for indigenous people in remote Australia: the requirements for sustainability. J Epidemiol Community Health. 2002;56(7):517-521.

121. Knight T, Smith J, Cropper S. Development Developing sustainable collaboration: learning from theory and practice. Prim Health Care Res Dev. 2001;2(3):139-148.

122. Glasgow RE, Vogt TM, Boles SM. Evaluating the public health impact of health promotion interventions: the RE-AIM framework. Am J Publ Health 1999;89(9):1322-1327

123. Eliason RN. Towards sustainability in village health care in rural Cameroon. Health Promot Int. 1999;14(4):301-306.

124. Olsen IT. Sustainability of health care: a framework for analysis. Health Pol Plann. 
$1998 ; 13(3): 287-295$

125. O'Loughlin J, Renaud L, Richard L, Gomez LS, Paradis G. Correlates of the sustainability of community-based heart health promotion interventions. Prev Med. 1998;27(5 Pt 1):702-712.

126. Cropper S. Collaborative Working and the Issue of Sustainability. London: Sage; 1996.

127. Stefanini A, Ruck N. Managing externally-assisted health projects for sustainability in developing countries. Int J Health Plann Manag. 1992;7(3):199-210.

128. Brinkerhoff DW, Goldsmith AA. Promoting the sustainability OF development institutions - a framework for strategy. World Dev. 1992;20(3):369-383.

129. Bossert TJ. Can they get along without us? Sustainability of donor-supported health projects in Central America and Africa. Soc Sci Med. 1990;30(9):1015-1023.

130. Bamberger MCS. Case Studies of Project Sustainability: Implications for Policy and Operations from Asian Experience. Washington, DC: The World Bank; 1990.

131. Bond GR, Drake RE, McHugo GJ, et al. Long-term sustainability of evidence-based practices in community mental health agencies. Adm Policy Ment Health. 2014;41(2):228-236.

132. El Bcheraoui C, Kamath AM, Dansereau E, et al. Results-based aid with lasting effects: sustainability in the Salud Mesoamerica Initiative. Glob Health. 2018;14(1):97.

133. Rasschaert F, Decroo T, Remartinez D, et al. Sustainability of a community-based anti-retroviral care delivery model - a qualitative research study in Tete, Mozambique. J Int AIDS Soc. 2014;17.

134. Welsh WN, Lin HJ, Peters RH, et al. Effects of a strategy to improve offender assessment practices: staff perceptions of implementation outcomes. Drug Alcohol Depend. 2015;152:230-238

135. Saviano M, Bassano C, Piciocchi P, Di Nauta P, Lettieri MJS. Monitoring viability and sustainability in healthcare organizations. Sustainability. 2018;10(10):3548.

136. Borgonovi E, Adinolfi P, Palumbo R, Piscopo GJS. Framing the shades of sustain ability in health care: pitfalls and perspectives from western EU countries. Sustainability. 2018;10(12):4439.

137. Aarons GA, Green AE, Trott E, et al. The roles of system and organizational leadership in system-wide evidence-based intervention sustainment: a mixed-method study. Adm Policy Ment Health. 2016;43(6):991-1008.

138. Ament SM, Gillissen F, Moser A, et al. Identification of promising strategies to sustain improvements in hospital practice: a qualitative case study. BMC Health Serv Res. 2014;14(1):641.

139. Dearing JW, Cox JG. Diffusion of innovations theory, principles, and practice. Health Aff. 2018;37(2):183-190.

140. Sarriot EYJ, Ryan L. The Sustained Health, Outcomes (SHOUT) Group. Taking the Long View: A Practical Guide to Sustainability Planning and Measurement in CommunityOriented Health Programming. Manual.Calverton, MD: Macro International Inc.; 2008.

141. Edwards JC, Feldman PH, Sangl J, Polakoff D, Stern G, Casey D. Sustainability of partnership projects: a conceptual framework and checklist. Joint Comm J Qual Patient Saf. 2007;33(12 SUPPL):37-47.

142. Goodman RM, McLeroy KR, Steckler AB, Hoyle RH. Development of level of institutionalization scales for health promotion programs. Health Educ Q. 1993;20(2):161-178.

143. Ford JH, Krahn D, Wise M, Oliver KA. Measuring sustainability within the veterans administration mental health system redesign initiative. Qual Manag Health Care. 2011;20(4):263-279.

144. Lennox L, Doyle C, Reed JE, Bell D. What makes a sustainability tool valuable, practical and useful in real-world healthcare practice? A mixed-methods study on the development of the Long Term Success Tool in Northwest London. BMJ Open. 2017;7(9).

145. Scheirer MA. Linking sustainability research to intervention types. Am J Publ Health 2013;103(4):e73-80

146. Nazar H, Nazar Z. Community pharmacy minor ailment services: pharmacy stakeholder perspectives on the factors affecting sustainability. Res Soc Adm Pharm.
2019;15(3):292-302.

147. King JC, Hibbs R, Saville CWN, Swales MA. The survivability of dialectical behaviour therapy programmes: a mixed methods analysis of barriers and facilitators to implementation within UK healthcare settings. BMC Psychiatr. 2018;18(1):302

148. Ibrahim U, Wan-Puteh SE. An overview of civil society organizations' roles in health project sustainability in Bauchi State, Nigeria. Pan Afr Med J. 2018;30:150.

149. Ehrhart MG, Torres EM, Green AE, et al. Leading for the long haul: a mixed-method evaluation of the Sustainment Leadership Scale (SLS). Implement Sci. 2018;13(1):17

150. Cooper BR, Bumbarger BK, Moore J. Sustaining evidence-based prevention programs: correlates in a large-scale dissemination initiative. Prev Sci. 2015;16(1):145-157.

151. Calhoun A, Mainor A, Moreland-Russell S, Maier RC, Brossart L, Luke DA. Using the program sustainability assessment tool to assess and plan for sustainability. Prey Chronic Dis. 2014;11 2014.

152. Doyle C, Howe C, Woodcock T, et al. Making change last: applying the NHS institute for innovation and improvement sustainability model to healthcare improvement. Implement Sci. 2013;8(1).

153. Maher L, Gustafson DH, Evans A. NHS Sustainability Model. NHS institute for innovation and improvement; 2010.

154. Savaya R, Elsworth G, Rogers P. Projected sustainability of innovative social programs. Eval Rev. 2009;33(2):189-205.

155. Hanh TT, Hill PS, Kay BH, Quy TM. Development of a framework for evaluating the sustainability of community-based dengue control projects. Am J Trop Med Hyg. 2009;80(2):312-318

156. Feinberg ME, Bontempo DE, Greenberg M. Predictors and level of sustainability of community prevention coalitions. Am J Prev Med. 2008;34(6):495-501.

157. Goodson P, Murphy Smith M, Evans A, Meyer B, Gottlieb NH. Maintaining prevention in practice: survival of PPIP in primary care settings. Put Prevention into Practice. Am J Prev Med. 2001;20(3):184-189.

158. Markström U, Svensson B, Bergmark M, Hansson L, Bejerholm U. What influences a sustainable implementation of evidence-based interventions in community mental health services? Development and pilot testing of a tool for mapping core components. J Ment Health. 2018;27(5):395-401.

159. Swain K, Whitley R, McHugo GJ, Drake RE. The sustainability of evidence-based practices in routine mental health agencies. Community Ment Health $J$ 2010;46(2):119-129.

160. Knapp H, Hagedorn H, Anaya $\mathrm{H}$. A five-year self-sustainability analysis of nurseadministered HIV rapid testing in Veterans Affairs primary care. Int J Std AIDS. 2014;25(12):837-843

161. Bopp M, Saunders RP, Lattimore D. The tug-of-war: fidelity versus adaptation throughout the health promotion program life cycle. J Prim Prev. 2013;34(3):193-207.

162. Machado Guimarães C, Crespo de Carvalho J. Strategic outsourcing: a lean tool of healthcare supply chain management. Strategic Outsourcing An Int $J$. 2013;6(2):138-166.

163. Carroll C, Patterson M, Wood S, Booth A, Rick J, Balain S. A conceptual framework for implementation fidelity. Implement Sci. 2007;2(1):40.

164. Van Daele T, Van Audenhove C, Hermans D, Van den Bergh O, Van den Broucke S. Empowerment implementation: enhancing fidelity and adaptation in a psychoeducational intervention. Health Promot Int. 2012;29(2):212-222.

165. Rokstad AMM, Vatne S, Engedal K, Selbæk G. The role of leadership in the implementation of person-centred care using Dementia Care Mapping: a study in three nursing homes. J Nurs Manag. 2015;23(1):15-26.

166. Bates I, Boyd A, Smith H, Cole DC. A practical and systematic approach to organisational capacity strengthening for research in the health sector in Africa. Health Res Pol Syst. 2014;12:11.

167. Cronin J, Bourke J. Value for money? An examination of the relationship between need and cost in intellectual disability services. Health Soc Care Community. 2017;25(3):1227-1236. 